\title{
Copper(II) Coordination Polymers Assembled from 2-[(Pyridin-3-ylmethyl)amino]ethanol: Structure and Magnetism
}

\author{
Jeong Hyeong Han, Jong Won Shin, ${ }^{*}$ and Kil Sik Min* \\ Department of Chemistry Education, Kyungpook National Lniversity, Daegu 702-701, Korea. ${ }^{\circ}$ E-mail: minksaknuackr \\ - Deparment of Chemistry. Kungpook National Unversitv, Daegu 702-701. Korea \\ Received Febriary 13, 2009, Accepted Afarch 31, 2009
}

\begin{abstract}
The one-dimensional coordination polymers, $\left[\mathrm{Cu}^{\mathrm{ll}}(\mathrm{L})\left(\mathrm{NO}_{3}\right)_{2}\right]_{n}$ (1) and $\left\{\left[\mathrm{Cu}^{\mathrm{ll}}(\mathrm{L}-\mathrm{H})\left(\mathrm{NO}_{3}\right)\right] \cdot 2 \mathrm{H}_{2} \mathrm{O}\right)_{2 n}$ (2), were synthesized from $\mathrm{Cu}\left(\mathrm{NO}_{3}\right)_{2} \cdot 3 \mathrm{H}_{2} \mathrm{O}$ and 2-[(pyridin-3-ylmethyl)amino]ethanol (L, PMAE) in methanol by controlling the molar ratio of copper(II) salt. Copper(II) ion in 1 has one pyridine group of PMAE whose an aninoethanol group coordinates adjacent copper(II) ion. As the pyridine group is bonded to neighboring copper(II) ion, $\mathbf{1}$ becomes a one-dimensional chain. Contrary to $\mathbf{1}$, the structure of $\mathbf{2}$ shows that the oxygen atom of ethoxide group is bridged between two copper(II) ions, which forms a dinuclear complex. Additionally, the pyridine group of PMAE included one dinuclear unit is coordinated to the other dimeric one each other, which leads to a one-dimensional polymer. Due to the structural differences, 1 exhibits weak antiferromagnetic interaction, while 2 shows strong antiferronagnetic interaction. Due to direct spin exchange via oxygen of PMAE 2 has a much strong spin coupling than 1
\end{abstract}

Key Words: Copper(II) complex. Ligand. Coordination polymer. Crystal structure. Magnetic properties

\section{Introduction}

The construction of multi-dimensional coordination polymers wia transition metal ions and organic building blocks is a rapidly growing area in chemistry. Coordination polymers with various frameworks, such as one-dimensional (1-D) chains and ladders. ${ }^{3}$ two-dimensional (2-D) grids and honeycombs. ${ }^{2}$ and three-dimensional (3-D) porous networks ${ }^{3}$ have been extensively studied. These polymeric compounds have been attracting much attention because of their potential applications for magnetic materials. ion exchange. luminescence. and gas storage. ${ }^{4}$

It has recognized that the metal centers and the counteranions can play significant roles in the self-assembly because they display a variety of features. i.e. geometry. charge. molecular shape and size. ${ }^{5}$ For example. chiral coordination polymers and macrocycles are constructed from mercury(II) halides and binaphthyl-bis(amidopyridyl) ligands by selfassembly. In this case the formation of polymers and macrocycles is attributed to the presence or absence of excess mercury'(II) halide. through a template effect. ${ }^{\text {sa }}$ Furthermore. the molecular loops were synthesized from the reaction of cis-( $\left(\mathrm{PEt}_{3}\right)_{2} \mathrm{Pt}(\mathrm{OTf})_{2}$ with bis(4-pyridy l)-functionalized freebase salen-type ligands via self-assembly. Due to the Zn(II)metalation of the salen-type ligands, the molecular loops convert to molecular squares. By using bis(3-py ridyl)-functionalized free-base salen-type ligand, a concentration-dependent dynamic equilibrium between the cyclic species is also observed, in which the metalation of free-base ligand shifted the equilibrium to the single dimeric species ${ }^{6 \mathrm{~b}}$ Very recently. a few silver(I) compounds with bis( + -py ridy l)dimethy Isilane (PDS) are exhibited that the PDS:Ag(I) ratios of the products are dependent upon the nature of the polyatomic anions $\left(\mathrm{NO}_{2}{ }^{-}\right.$. $\mathrm{NO}_{3}^{-} . \mathrm{PF}_{6}^{-}$. and $\mathrm{CF}_{3} \mathrm{SO}_{3}^{-}$). regardless of the molar ratio of reactants.

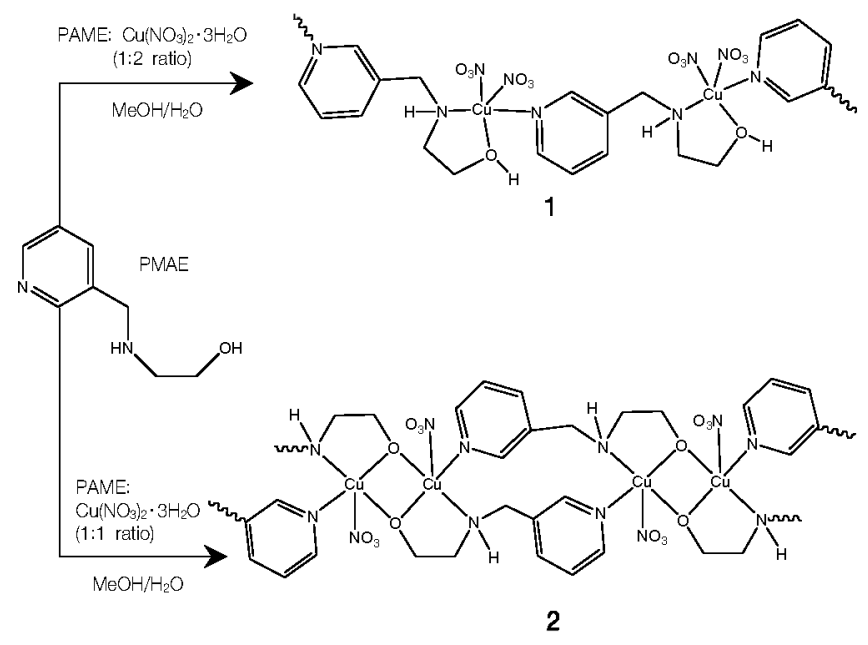

Scheme 1

The use of organic ligands containing hydroxyl and py ridine groups is very useful for obtaining the desired coordination polymers. because the hydroxyl group is converted to the deprotonated alcohol (ethoxide) group easily via coordination to metal ion. Thus the ethoxide group can basically link two metal ions to form dimeric unit. ${ }^{8}$ Furthermore. the pyridine group can also be used to connect with metal ions to construct network structures. Finally we chose bifunctional 2-[(pyridin-3-ylmethyl)amino]ethanol (PMAE) ligand for self-assembly as organic building block. The molecular geometry and flexibility of multi-dentate PMAE can be induced interesting coordination framework structures. In this paper. in an effort to explore the role of the concentration of metal salt in the self-assenbly, the reactions of $\mathrm{Cu}\left(\mathrm{NO}_{3}\right)_{2}$. $3 \mathrm{H}_{2} \mathrm{O}$ with $\mathrm{PMAE}$ were performed and characterized. Consequently. we have obtained new framework structures depending upon the molar ratio of copper(II) salt (Scheme 1). Herein. 
we report the synthesis. crystal structures. and magnetic properties of novel one-dimensional copper(II) coordination polymers. $\left[\mathrm{Cul}^{\mathrm{II}}\left(\mathrm{C}_{8} \mathrm{H}_{12} \mathrm{~N}_{2} \mathrm{O}\right)\left(\mathrm{NO}_{3}\right)_{2}\right]_{n}$ (1) and $\left\{\left[\mathrm{Cul}^{\mathrm{II}}\left(\mathrm{C}_{8}\right.\right.\right.$ $\left.\left.\mathrm{H}_{1]} \mathrm{N}_{2} \mathrm{O}\right)\left(\mathrm{NO}_{3}\right)\right] \cdot 2 \mathrm{H}_{2} \mathrm{O}$; 2 (2). whose topology and dimensionality are dependent upon the molar ratio of $\mathrm{Cu}\left(\mathrm{NO}_{3}\right)_{2}$. $3 \mathrm{H}_{-} \mathrm{O}$.

\section{Experimental Section}

Materials and Measurements. All chemicals and solvents used in the syntheses were of reagent grade and were used without further purification. 2-[(Pýridin-3-ylmethỵl)amino] ethanol (PMAE. $\mathrm{C}_{8} \mathrm{H}_{1} \mathrm{~N}_{2} \mathrm{O}$. L) was prepared by a literature method. ${ }^{3}$ Infrared spectra were recorded with a ThermoFisher Scientific IR200 FT-IR spectrometer $\left( \pm 1 \mathrm{~cm}^{-1}\right)$. Elemental analyses were performed by the analytical laboratory of Kyungpook National University. Magnetic susceptibilities were measured in an applied field of 1000 Oe between 2 and $300 \mathrm{~K}$ on a Quantum Design MPMS superconducting quantum interference device (SQUID) magnetometer. Diamagnetic corrections were made by using Pascal's constants ( 147.35 (1) and $150.35 \times 10^{-6}$ (2) emu/mol).

Preparation of $\left[\mathrm{Cu}^{\mathrm{I}}(\mathrm{L})\left(\mathrm{NO}_{3}\right)_{2}\right]_{\mathbf{n}}$ (1). To a MeOH solution $(10 \mathrm{~mL})$ of $\mathrm{Cu}\left(\mathrm{NO}_{3}\right)_{2} \cdot 3 \mathrm{H}_{2} \mathrm{O}(316 \mathrm{mg}, 1.308 \mathrm{mmol})$ was added dropwise a $\mathrm{MeOH} / \mathrm{H}_{2} \mathrm{O}$ mixture solution ( $/ / \mathrm{s}, 8: 2,10$ $\mathrm{mL}$ ) of 2-[(py ridin-3-ylmethyl)amino]ethanol (L. $100 \mathrm{mg}$. $0.65+\mathrm{mmol}$ ). and the color became dark blue and the solution was stirred for $30 \mathrm{~min}$ at room temperature. The solution was allowed to stand at room temperature until dark blue microcrystals of 1 formed, these were filtered off, washed with methanol. and dried in air. Yield: $170 \mathrm{mg}(77 \%)$. IR (KBr): 3260.3204 .3062 . 2966. 2897. 2766. 1615. 1462. 1385. 1312. 1021. 810, $707 \mathrm{~cm}^{-1}$. Anal. Calcd for $\mathrm{C}_{8} \mathrm{H}_{1} \mathrm{CuN}_{4} \mathrm{O}: \mathrm{C}, 28.28$; H. 3.56: N 16.49. Found: C. $28.72:$ H. 3.57: N. 16.41

Preparation of $\left\{\left[\mathbf{C u}^{\mathrm{II}}(\mathbf{L}-\mathrm{H})\left(\mathrm{NO}_{3}\right)\right] \cdot \mathbf{2 H}_{\mathbf{2}} \mathrm{O}\right\}_{2 \mathrm{n}}(\mathbf{2})$. To a MeOH solution ( $10 \mathrm{~mL}$ ) of $\mathrm{Cu}\left(\mathrm{NO}_{3}\right)_{2} \cdot 3 \mathrm{H}_{2} \mathrm{O}(158 \mathrm{mg} .0 .654 \mathrm{mmol})$ was added dropwise a $\mathrm{MeOH} / \mathrm{H}_{2} \mathrm{O}$ mixture solution (v/v: $8: 2$, $10 \mathrm{~mL}$ ) of 2-[(pyridin-3-ylmethyl)amino]ethanol (L. $100 \mathrm{mg}$. $0.654 \mathrm{mmol}$ ). and the color became dark green. and the solution was stirred for $30 \mathrm{~min}$ at room temperature. The solution was allowed to stand at room temperature until dark green microcrystals of 2 formed. these were filtered off. washed with methanol. and dried in air. Yield: $68 \mathrm{mg}(34 \%)$. IR (KBr): 3400, 3215. 3162. 3048. 2958, 2917, $2857,1646$. 1613. 1384. 1066,806.707 $\mathrm{cm}^{-1}$. Anal Calcd for $\mathrm{C}_{8} \mathrm{H}_{1} \leqslant \mathrm{CuN}_{3} \mathrm{O}_{6}$ : C. $30.72: H, 4.83:$ N. 13.43. Found: C. 30.89: H. 4.77: N. 13.40 .

X-ray Crystallographic Data Collection and Refinement. Single crystals of 1 and 2 were mounted on a Bruker SMART APEX CCD-based diffractometer (Korea Basic Science Institute. Chonju Branch). X-ray data for 1 and $\mathbf{2}$ were collected at $293(2) \mathrm{K}$ and using Mo $\mathrm{K}$. radiation $(i=0.71073$ A. graphite monochromator). The raw data were processed to give structure factors using the Bruker SAINT program and corrected for Lorentz and polarization effects. ${ }^{10}$ No absorption corrections were applied. The crystal structures were solved by direct methods. " and refined by full-matrix least-squares refinement using the SHELXL97 computer program." All
Table 1. Crystal Data and Structure Refimement for 1 and 2

\begin{tabular}{|c|c|c|}
\hline Compound & 1 & 2 \\
\hline Empirical formula & $\mathrm{C}_{8} \mathrm{H}_{12} \mathrm{CuN}_{4} \mathrm{O}$ & $\mathrm{C}_{8} \mathrm{H}_{1} \mathrm{CuN}_{3} \mathrm{O}_{6}$ \\
\hline Formula weight & 339.76 & 312.77 \\
\hline Crystal system & Monoclinic & Monoclinic \\
\hline Space group & $P 2{ }_{1} / C$ & $\mathrm{C} 2 / \mathrm{c}$ \\
\hline$a, \AA$ & $10.7320(6)$ & $15.0906(16)$ \\
\hline$b, \AA$ & $7.6759(4)$ & $13.9216(14)$ \\
\hline$c, \AA$ & $15.0672(8)$ & $13.7673(14)$ \\
\hline$\beta$, deg & $103.090(1)$ & $121.30(2)$ \\
\hline $\mathrm{I}: \AA^{3}$ & $1208.95(11)$ & $2471.4(4)$ \\
\hline$Z$ & 4 & 8 \\
\hline$d_{\mathrm{calc}}\left(\mathrm{g} \mathrm{cm}^{-3}\right)$ & 1.867 & 1.681 \\
\hline$\lambda, A$ & 0.71073 & 0.71073 \\
\hline$T, \mathrm{~K}$ & $293(2)$ & $293(2)$ \\
\hline$\mu, \mathrm{mm}^{-1}$ & 1.848 & 1.792 \\
\hline$F(000)$ & 692 & 1288 \\
\hline Reflections collected & 8666 & 9048 \\
\hline Independent reflections & 2987 & 3067 \\
\hline Reflections with $I>2 \sigma(I)$ & 1926 & 1759 \\
\hline Goodness-of-fit on $F^{2}$ & 1.148 & 1.124 \\
\hline Final $R$ indices $[I>2 \sigma(I)]$ & $\begin{array}{l}R_{1}=0.0455 \\
w R_{2}=0.0832\end{array}$ & $\begin{array}{l}R_{1}=0.0779 \\
w R_{2} 0.2080\end{array}$ \\
\hline$R$ indices (all data) & $\begin{array}{l}R_{1}=0.0938 \\
w R_{2}=0.1382\end{array}$ & $\begin{array}{l}R_{1} 0.1172 \\
w R_{1}=0.2625\end{array}$ \\
\hline
\end{tabular}

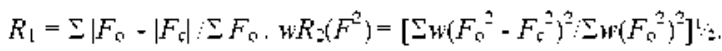

Table 2. Selected Bond Distances (Á) and Angles (") for 1

\begin{tabular}{llll}
\hline Cul-Nl & $2.021(4)$ & Cul-N2 & $1.981(5)$ \\
Cul-Ol & $1.992(4)$ & Cul-O2 & $2.281(4)$ \\
Cul-O5 & $1.976(4)$ & $\mathrm{N3-O} 2$ & $1.252(6)$ \\
N3-O3 & $1.222(5)$ & N3-O4 & $1.275(6)$ \\
N4-O5 & $1.279(6)$ & N4-O6 & $1.242(6)$ \\
N4-O7 & $1.214(6)$ & Cl-Ol & $1.420(7)$ \\
\hline N1-Cul-N2 & $169.27(18)$ & N1-Cul-Ol & $82.28(16)$ \\
N1-Cul-O2 & $100.09(17)$ & N1-Cul-O5 & $92.35(16)$ \\
N2-Cul-Ol & $91.42(17)$ & N2-Cul-O2 & $88.24(16)$ \\
N2-Cul-O5 & $94.05(17)$ & Ol-Cul-O2 & $87.40(17)$ \\
O1-Cul-O5 & $174.52(16)$ & O2-Cul-O5 & $92.46(16)$ \\
O2-N3-O3 & $122.4(5)$ & O2-N3-O4 & $117.1(5)$ \\
03-N3-O4 & $120.4(5)$ & O5-N4-O6 & $118.5(4)$ \\
05-N4-O7 & $119.9(5)$ & O6-N4-O7 & $121.6(5)$ \\
\hline
\end{tabular}

Table 3. Selected Bond Distances (A) and Angles (") for 2

\begin{tabular}{|c|c|c|c|}
\hline Cul-Nl & $2.035(5)$ & Cul-N2 & $2.014(5)$ \\
\hline $\mathrm{Cul}-\mathrm{Ol}$ & $1.912(5)$ & Cul-Ol' & $1.944(5)$ \\
\hline Cul-O2 & $2.344(6)$ & $\mathrm{Cul} \cdots \mathrm{Cul}{ }^{\mathrm{t}}$ & $2.962(1)$ \\
\hline $\mathrm{Cl}-\mathrm{Ol}$ & $1.412(7)$ & $\mathrm{O} 2-\mathrm{N} 3$ & $1.255(15)$ \\
\hline $\mathrm{Ol}-\mathrm{Cul}-\mathrm{Nl}$ & $84.1(2)$ & Ol-Cul-N2 & $176.6(2)$ \\
\hline $\mathrm{Ol}-\mathrm{Cul}-\mathrm{Ol}^{\prime}$ & $79.6(2)$ & $\mathrm{Ol}-\mathrm{Cul}-\mathrm{O}_{2}$ & $92.7(3)$ \\
\hline $\mathrm{Ol}-\mathrm{Cul}-\mathrm{Cul}{ }^{1}$ & $40.2(2)$ & NI-Cul-O2 & $97.7(2)$ \\
\hline $\mathrm{N} 1-\mathrm{Cul}-\mathrm{N} 2$ & $98.4(2)$ & $\mathrm{N} 2-\mathrm{Cul}-\mathrm{O} 2$ & $89.3(2)$ \\
\hline Cul-Ol-Cul] & $100+(2)$ & $\mathrm{N} 3-\mathrm{O} 2-\mathrm{Cul}$ & $118.5(14)$ \\
\hline
\end{tabular}

Symmetry transformations used to generate equivalent atoms: (i) $-\mathrm{x}+1$. $-y, z-2$. 
non-hydrogen atoms were refined anisotropically. All hydrogen atoms were positioned geometrically and refined using a riding model. Due to disorder the two noncoordinated oxygen atoms of nitrate anion and two water molecules for 2 were treated with the SQUEEZE routine in the program PLATON ${ }^{13}$ and omitted from the final refinements, but are included in the computation of intensive properties. The crystallographic data and the result of refinements are summarized in Table 1.

\section{Results and Discussion}

Synthesis and Chanacterization. The reaction of PMAE with $\mathrm{Cu}\left(\mathrm{NO}_{3}\right)_{2}=3 \mathrm{H}_{2} \mathrm{O}$ in $1: 2$ and $1: 1$ ratios in $\mathrm{MeOH} / \mathrm{H}_{2} \mathrm{O}$ affords the polymeric compounds. $\left[\mathrm{Cu}{ }^{\mathrm{I}}(\mathrm{L})\left(\mathrm{NO}_{3}\right)_{2}\right]_{\mathrm{n}}(\mathbf{1})$ and $\left\{\left[\mathrm{Cu}^{\mathbb{I}}(\mathrm{L}-\mathrm{H})\left(\mathrm{NO}_{3}\right)\right] \cdot 2 \mathrm{H}_{3} \mathrm{O}\right\}_{3 \mathrm{n}}$ (2) in good yield. respectively. Generally, the hydrolysis of hydroxyalkyl group occurs via coordination to metal ions under mild conditions. Interestingly, two one-dimensional coordination polymers 1 and 2 have been obtained from the different ratios of PMAE and copper(II) ion. That is. 1 is formed in a 1:2 ratio (PMAE/ copper) and has the hydroxyl group of PMAE intact, while 2 is obtained in a $1: 1$ ratio and shows the deprotonated oxygen atom bridged between the copper(II) ions in a dimeric unit. This can be attributed to the increased acidity of the reaction solution for the self-assembly of 1 . due to the hydrolysis by excess copper(II) salt. Additionally the excess amount of nitrate anions can help to crystallize in $\mathbf{1}$ without the deprotonation of PMAE as two nitrate anions bind to one copper(II) ion. The compositions of $\mathbf{1}$ and $\mathbf{2}$ were determined by elemental analysis, infrared, and X-ray diffraction. The IR spectnum (KBr pellet) of 1 shows $v_{-I H}$ of the PMAE ligand at $3260 \mathrm{~cm}^{-1}$ and $\mathrm{V}_{\mathrm{NH}}$ of the PMAE at $320+\mathrm{cm}^{-1}$. The IR spectrum (KBr pellet) of 2 shows $v_{\mathrm{H}}$ of the water molecules at $3400 \mathrm{~cm}^{-1}$ and $v_{\mathrm{NH}}$ of the PMAE at $3215 \mathrm{~cm}^{-1}$. Unlike compound 1. the hydroxyl group of the PMAE ligand in 2 is disappeared at around $3260 \mathrm{~cm}^{-1}$. Both compounds display the coordinated nitrate anion peaks at 1385 and $1384 \mathrm{~cm}^{-1}$. respectively

$\mathrm{X}$-ray Cystal Structure of 1 . The polymeric stnicture of $\mathbf{1}$ is shown in Figure 1. In the structure, copper(II) ion is coordinated with a secondary nitrogen and a hydroxyl oxygen of a PMAE and two oxygen atoms of nitrate ions as well as a pyrridine group of PMAE whose an aminoethanol group bonds adjacent copper(II) ion. The $\mathrm{Cu}-\mathrm{N}_{\text {secondary }}$ and $\mathrm{Cu}-\mathrm{N}_{\mathrm{py} \text { Tume }}$ bond distances are 2.021(4) and 1.981(5) A. respectively. For the coordinated nitrate ions. two $\mathrm{Cl}-\mathrm{O}$ bond distances are $1.976(4)$ and 2.281(4) $\mathrm{A}$, respectively. Furthermore. the $\mathrm{Cu}-\mathrm{O}_{\text {thy }}$ oxy bond distance is $1.992(4) \AA$. The copper(II) ion is $0.069(2) \AA$ out of the square-coordination $\mathrm{N}_{2} \mathrm{O}_{2}$ plane toward $\mathrm{O}_{2}$ atom. Thus. the coordination geometry around copper(II) ion can be best described as a distorted square pyramid. All PMAEs link two copper(II) ions because the pyridine group of the PMAE ligand included a copper(II) ion coordinates an adjacent copper(II) ion. Therefore. the structure of 1 becomes a one-dimensional zigzag coordination polymer. which extends parallel to the $c$ axis. The separation of $\mathrm{Cu} \cdots \mathrm{Cu}$ within a chain is 7.763 (1) $\mathrm{A}$ (Figure 1). The shortest interchain $\mathrm{Cu} \cdots \mathrm{Cu}$ distance is $6.434(1) \AA$. In addition. the coordinated PMAE

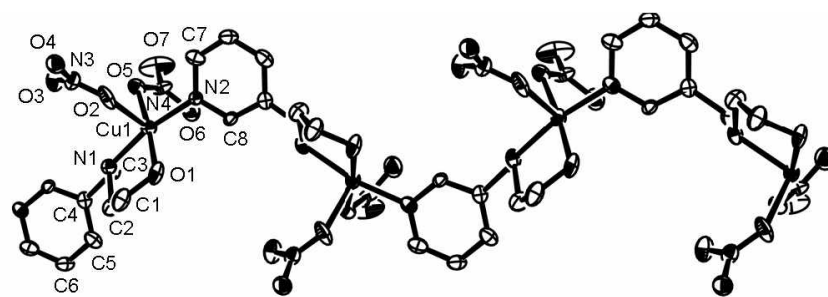

Figure 1. View of the polymeric structure of $\mathbf{1}$ showing the atomlabeling scheme and $50 \%$ thermal ellipsoids. Hydrogen atoms are omitted for clarity.

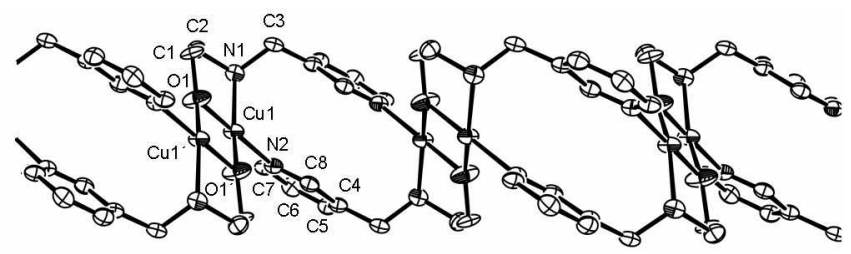

Figure 2. View of the polymeric structure of 2 showing the atomlabeling scheme and $30 \%$ themal ellipsoids. Hydrogen atoms, water molecules and nitrate anions are omitted for clarity $c^{\prime}=-\mathrm{x}+\mathrm{l},-\mathrm{y}$, $-2+2)$.

(a)

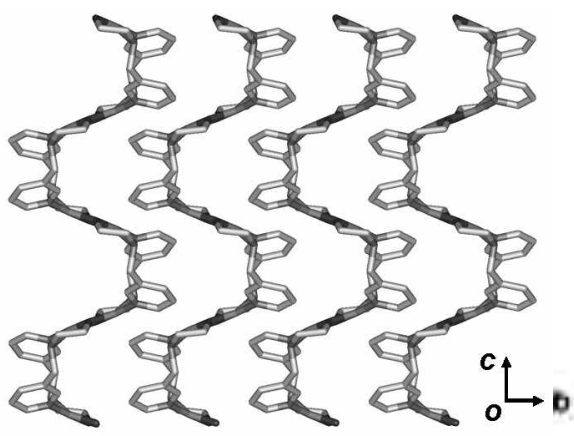

(b)

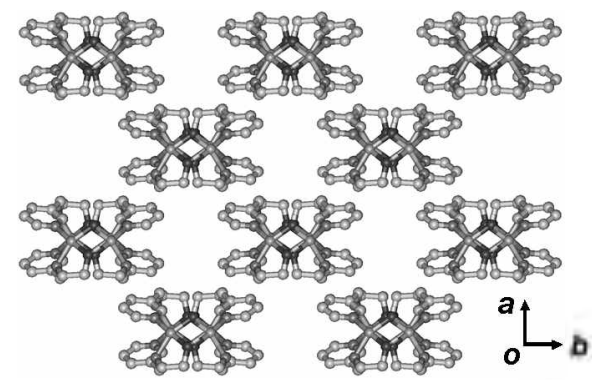

Figure 3. Perspective views of 2 showing oftset face-to-face $\pi-\pi$ interactions between the one-dimensional polymers: (a) 2-D and (b) $3-D$.

ligand is involved in the hydrogen bonding interactions with nitrate ions: $\mathrm{N} 1 \cdots \mathrm{O}+(-\mathrm{x}+2,-\mathrm{y},-\mathrm{z}+2), 3.07 \mathrm{l}(6) \mathrm{A}$ : $\angle \mathrm{N} 1-\mathrm{H} 2-$ $\mathrm{O} 4,151^{\circ}: \mathrm{Ol} \cdots \mathrm{O}+(-\mathrm{x}+2 . \mathrm{y}+1 / 2 .-\mathrm{z}+3 / 2), 2.7+6(5) \mathrm{A} ; \angle \mathrm{Ol}-$ $\mathrm{Hl}-\mathrm{O} 4,175^{\circ}$. Due to the $\mathrm{N}-\mathrm{H}^{\cdots} \mathrm{O}$ and $\mathrm{O}-\mathrm{H}^{*} \mathrm{O}$ hyddrogenbonding interactions. ${ }^{1+4}$ the framework structure of 1 forms a three-dimensional network (Figures S1-3).

$\mathbf{X}$-1ay Ciystal Stucture of 2. The polymeric structure of $\mathbf{2}$ is represented in Figure 2. In the structure. copper(II) ion is bonded with a secondary nitrogen and an ethoxide oxygen of 


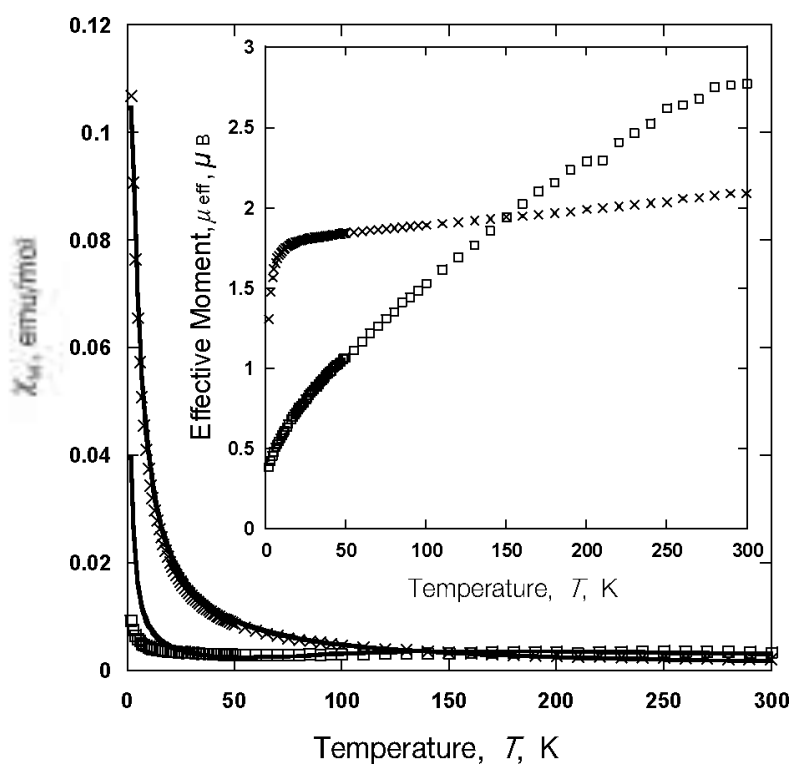

Figure $4 . \lambda T$ ) for $1(x)$ and $2(\sqsupset)$. The solid lines are the best-fit curves to eqs 1 and 2 , respectively [Inset: $\mu_{\mathrm{en}}(T)$ ]

a PMAE and one oxygen atoms of nitrate ion as well as a pyridine ring of PMAE included a neighboring copper(II) ion. The $\mathrm{Cu}-\mathrm{N}_{\text {seconilayy }}$ and $\mathrm{Cu}-\mathrm{N}_{\text {pyrtiline }}$ bond distances are $2.035(5)$ and $2.01+(5) \AA$. respectively. For the coordinated nitrate ion. one $\mathrm{Cu}-\mathrm{O}$ bond distances is $2.344(6) \mathrm{A}$. Furthermore. the $\mathrm{Cu}-\mathrm{O}_{\text {ethoxule }}$ bond distances are $1.912(5) \mathrm{A}$ for $\mathrm{Ol}$ and $1.944(5)$ $A$ for $\mathrm{Ol}^{\prime}(-\mathrm{x}+1,-\mathrm{y},-\mathrm{z}+2)$, respectively. The copper(II) ion is $0.163(2)$ A out of the square-coordination $\mathrm{N}_{2} \mathrm{O}_{2}$ plane toward $\mathrm{O} 2$ atom. Likewise 1 . the coordination geometry around copper(II) ion is described as a distorted square py ranid

The square planar copper(II) centers are bridged equally by the oxygen atoms of ethoxide. which leads to a dinuclear unit. Furthermore, the pyridine group of PMAE included one dinuclear unit is coordinated to the other dimeric one each other, which gives rise to a one-dimensional wavelike chain (Figure 3a). The separations of $\mathrm{Cu}^{\prime} \cdot \mathrm{Cu}$ within a dimeric unit and between the dimeric moieties in a chain are 2.962(1) and 5.813 (2) A, respectively (Figure 2). The shortest interchain $\mathrm{Cu}$ " $\mathrm{Cu}$ distance is $7.415(\mathrm{l}) \AA$. In the dimeric unit the dihedral angle between the pyridine rings is $\theta=18.1(4)^{\circ}$ and the interplanar separation between the pyridine rings is $3.04(1)-3.87$ (1) $\AA$ as well as centroid separation is $3.506 \AA$. In addition to. between the inter-chains the dihedral angle of the pyridine rings is $\theta=0.0^{\circ}$ and the interplanar separation between the pyridine rings is $3.48(1)-3.50(1) \mathrm{A}$ as well as centroid separation is $3.601 \AA$. In case of 2 due to the offset face-to-face $\pi-\pi$ interactions, the structure becomes a threedimensional network (Figure 3 ).

Magnetic Properties of 1 and 2. Variable-temperature $2-300 \mathrm{~K}$ magnetic susceptibility, $\chi$ measurements on solid samples of 1 and 2 have been performed on a SQUID magnetomerter (external field $1000 \mathrm{Oe}$ ). For compound 1 . at room temperature, the effective moment. $\mu_{\text {etif }}\left[=(8 \chi T)^{1:}\right]$ is $2.09 \mu_{\mathrm{B}} / \mathrm{Cu}$ and $\mu_{\mathrm{zff}}(T)$ decreases monotonically with decreasing temperature to $1.79 \mu_{\mathrm{B}}$ at $20 \mathrm{~K}$. and then rapidly decreases to $1.3 \mathrm{I} \mu_{\mathrm{B}}$ at $2 \mathrm{~K}$. indicating the presence of a very weak anti- ferromagnetic interaction within the one-dimensional (1-D) chain (Figure 4). $\not(T)$ for 1 was fit to a numerical expression. eq 1 . derived by Bonner and Fisher for a uniform $S=1 / 2$ infinite chain model $\left[H=-J\left(\sum \mathbf{S}_{1} \cdot \mathbf{S}_{1+1}\right)\right] .{ }^{16}$ The best fit had $J / k_{\mathrm{B}}$ of $-2.5 \mathrm{~K}\left(-1.74 \mathrm{~cm}^{-1}\right), g=2.25, \theta=-0.1 \mathrm{~K}$ and the temperature independent paramagnetisn, TIP $=60 \times 10^{-6} \mathrm{emu} / \mathrm{mol}$. The weak interaction can be attributed to a long distance between the neighboring copper(II) ions in the l-D chain $(7.763 \mathrm{~A})$.

$$
\chi=\left[\mathrm{Ng}^{2} t t_{\mathrm{B}}^{2} k_{\mathrm{E}}(T-\theta)\right] \mathrm{F}(T)+\mathrm{TIP}
$$

where

$\mathrm{F}(T)=\left[0.25+0.074975\left(k / / k_{\mathrm{B}} T\right)+0.075235\left(k / / k_{\mathrm{B}} T\right)^{-}\right] /[1+$ $\left.0.9931\left(\mid / / k_{\mathrm{B}} T\right)+0.172135\left(\mid / / k_{\mathrm{B}} T\right)^{2}+0.757825\left(\mid / / k_{\mathrm{B}} T\right)^{3}\right]$

Compound 2 has a roon temperature the effective monent $\mu_{\mathrm{eff}}$ of $2.77 \mu_{\mathrm{E}} / \mathrm{Cu}_{2}: \mu_{\mathrm{efr}}(T)$ decreases gradually with a decrease in the tentperature to $0.382 l_{\mathrm{B}}$ at $2 \mathrm{~K}$ (Figure 4), indicative of a strong antiferromagnetic interaction within the dimeric copper(II) unit in the 1-D chain. $\not(T)$ for 2 was fit to an analytical expression. eq 2, derived by Bleaney and Bowers for a coupled $S=1 / 2$ dimeric unit $\left[H=-2 J\left(\mathbf{S}_{1} \cdot \mathbf{S}_{2}\right)\right]$.

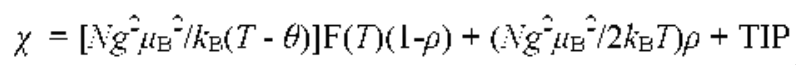

where $\mathrm{F}(T)=\left[2 \exp \left(2 J / k_{\mathrm{B}} T\right)\right] /\left[1+3 \exp \left(2 J / k_{\mathrm{B}} T\right)\right]$

The best fit had $J / k_{\mathrm{B}}$ of $-145 \mathrm{~K}\left(-101 \mathrm{~cm}^{-1}\right), g=2.30 . \theta=-2.5$ $\mathrm{K}, \theta=0.079$ and the temperature independent paramagnetisin. $\mathrm{TIP}=5.5 \times 10^{-4} \mathrm{emu} / \mathrm{mol}$. This coupling constant $(J)$ is comparable to that of $[\mathrm{Cu}(\mathrm{EAEP})(\mathrm{OH})]_{2}\left(\mathrm{ClO}_{4}\right)_{2}\left(J=-130 \mathrm{~cm}^{-1}\right)$. a related copper(II) complex with a hydrooxo bridge $(\mathrm{EAEP}=$ 2 -(2-ethylaninoethyl)pyridine). ${ }^{18}$ It has well known that the magnitude of coupling constants in oxy gen-bridged copper(II) dimers is significantly correlated the $\mathrm{O}-\mathrm{Cu}-\mathrm{O}$ angle including planarity about the bridging oxygen atom. $\mathrm{Cu}^{*} \mathrm{Cu}$ distance. tetrahedral distortion of the $\mathrm{N}_{2} \mathrm{CuO}_{2}$ plane. and magnitude of axial interactions. ${ }^{8,18-15}$ The strong antiferromagnetic interaction is attributed to direct spin exchange wia the bridged oxygen atoms within the copper(II) dimeric unit in the chain. This interaction is ca. 2 orders of magnitude stronger than the weak antiferromagnetic interaction $(-2.5 \mathrm{~K})$ between the copper(II) ions in 1.

\section{Conclusion}

New copper(II) coordination poly'mers. $\left[\mathrm{Cu}^{\mathrm{II}}(\mathrm{L})\left(\mathrm{NO}_{3}\right)_{2}\right]_{\mathfrak{n}}$ (1) and $\left\{\left[\mathrm{Cu}{ }^{\mathrm{II}}(\mathrm{L}-\mathrm{H})\left(\mathrm{NO}_{3}\right)\right] \cdot 2 \mathrm{H}_{2} \mathrm{O}\right\}_{2 \mathrm{nl}}(2)$ have been prepared and characterized $(\mathrm{L}=2$-[(pyrridin-3-ỵlmethy l)amino] PMAE), in which their framework structures are dependent upon the molar ratio of copper(II) salt. Compound 1 becomes a one-dimensional zigzag chain which extends parallel to the $c$ axis. while 2 shows that a dinuclear unit bridged with the oxygen atom of ethoxide group of PMAE is coordinated to the other dimeric one through the pyridine ring of PMAE, which leads to an altemative one-dimensional wavelike chain. Compound 1 shows weak antiferromagnetic coupling. while compound 2 shows strong antiferromagnetic coupling due to 
direct spin exchange via the bridging oxygen atom of PMAE.

Acknowledgments. This work was supported by the Korea Research Foundation Grant funded by the Korean Government (MOEHRD. Basic Research Promotion Fund) (KRF-2007$331-C 00144)$.

Supporting Information. The crystal packing structures of 1 and 2 (Figures S1-4). Cry stallographic data (excluding structure factors) for the stnictures reported in this paper have been deposited with the Cambridge Crystallographic Data Centre as supplementary publication nos. CCDC-720019 (for 1) and CCDC-720020 (for 2). Copies of the data can be obtained free of charge on application to CCDC, 12 Union Road. Cambridge CB2 IEZ. UK [Fax (internat.) +4+-1223/336-033: E-mail: depositáccdc.cam.ac.uk].

\section{References}

1. (a) Fujita, W.; Awaga, K.; Kondo, R.; Kagoshima, S. J. Ant. Chem. Soc. 2006, 128, 6016. (b) Shapiro, A.; Landee, C. P.; Tunibull, M. M.; Jonet, J.: Deumal, M: Novoa, J. J.: Robb, M. A.; Lewis, W. $J$. An. Chem. Soc. 2007, 129, 952. (c) Yi, L. Yang, X: Lu, T.; Cheng, P. Crvst. Growth Des. 2005, 5, 1215. (d) Withersby, M. A.; Blake, A. J.: Champness, N. R; Cooke, P. A.; Hubberster, P; Li, W: Schröder, M. Inorg. Chent. 1999, 38 , 2259 .

2. (a) Kondo, M:: Shimamura, M.; Noro, S.-I: Minakoshi, S.: Asami, A.; Seki, K.; Kitagawa, S. Chem. Afater: 2000, 12, 1288. (b) Ko, J. W; Min, K. S.; Sul, M. P. Inorg. Chem. 2002, 41, 2151 . (c) Choi, H. J.: Sul, M. P. J. Am. Chem. Soc. 1998, 120, 10622.

3. Bradshaw; D.; Claridge, I. B.; Cussen, E. J; Prior; T. J; Rosseinsky, M. J. Acc. Chem. Res. 2005, 38, 273.

4. (a) Numata, Y; Inoue, K.; Baranov, N.; Kurmoo, M; Kikuchi, K. J. Ant. Chem. Soc. 2007, 129, 9902. (b) Milon, J.; Daniel, M.-C.: Kaiba, A.; Guionnean, P; Brandès, S.; Sutter, J.-P. J.Am. Chem. Soc 2007, 129, 13872. (c) Ishii, N.: Okamura, Y: Chiba, S. Nogami, T.: Ishida, T. J. Am. Chem. Soc. 2008, 130, 24. (d) Yaghi, O. M.: Li, H. J.Am. Chem. Soc 1996, 118, 295 (e) Bauer,
C. A.: Timofeeva, T. V: Settersten. T. B.: Patterson, B. D.: Liu, V. H.: Simmons, B. A.; Allendorf, M. D. J. Am. Chem. Soc. 2007, 129, 7136. (f) Gao, H.-L.: Yi, L.: Zhao, B.: Zhao, X.-O.: Cheng, P.; Liao, D.-Z.; Yan, S.-P. horg. Chem. 2006, 45, 5980. (g) Chen, B.: Ji, Y: Xue, M.: Fronczek, F. R.: Hurtado, E. J: Mondal, I. U.; Liang, C.: Dai, S. Inorg. Chem. 2008, 47, 5543.

5. (a) Strauss, S. H. Chem. Rev 1993, 93, 927. (b) Lankshear, M. D.; Beer, P. D. Acc. Chemt Res. 2007, 10, 657. (c) Kang, S. O.; Begum, R. A.; Bowman-James, K. Angew: Chen. Int. Ed. 2006, 45, 7882. (d) Schurke, P.: Freeman, J. C.: Dabrowski, M. I.; Atkins, W. M. J. Biol. Chem. 1999, 274, 27963.

6. (a) Burchell, T. T.; Puddephatt, R. I. Inorg Chem 2005, th, 3718. (b) Sun, S.-S.; Stern, C. L ; Nguyen, S. T.; Hupp, I. T. J. Am. Chem Soc. 2004, 126,6314.

7. Lee, I. W.: Kim, E. A.: Kim, Y. I.; Lee, Y. A.; Park, Y.: Iung, O.-S. Inolg. Chem 2005, 44,3151

8. Curtis, N. F.; Einstein, F. W. B.; Morgan, K. R: Willis, A. C. horg. Chem. 1985, 2f, 2026.

9. Li, G.; Qian, X.; Cui, J.: Huang, Q.: Cui, D.; Zhang, R.; Lill, F. J. Flnot Chem. 2006, 127, 182.

10. Saint Plus, y. 6.02; Bruker Analytical X-ray: Madison, WI, 1999

11. Sheldrick, G. M. Acta Cnstallogr, Sect . $1990, \$ 6,467$.

12. Sheldrick, G. M. SHEL1297: Program for the Crustal Stricture Refmement, University of Göttingen: Gemany, 1997.

13. Spek, A. L. J. Appl. Crystallogr: 2003, 36,7.

14. (a) Desiraju, G. R. Angew: Chem. Int. Ed. Engl 1995, 34, 2311. (b) Aakeroy, C. B. Acta Civst. 1997, B53,569 (c) Archer, E. A.; Sochia, A. E.: Krische, M. T. Chem. Eur. J. 2001, 7, 2059.

15. (a) Desiraju. G. R. Cnstal Engineering: The Design of Organic Solids; Elsevier: New York, 1989; chap. 4. (b) Shetty, A. S.; Zhang, I.; Moore, J. S. J. Am. Chem. Soc 1996, 118, 1019. (c) Temings, W. B.: Farrell, B. M.; Malone, J. F. Acc. Chem Res. $2001,34,885$.

16. (a) Bonner, J. C.; Fisher, M. E. P/ys. Rev 1964, A135, 640. (b) Estes, G. A.: Gavel, D. P.: Hatfield, W. E.: Hodgson, D. J. Inoig. Chem. 1978, 17, 1415

17. Bleaney, B.; Bowers, K. D. Proc: Rov. Soc. (London) Sen A $1952,214,451$

18. Kalu1, O. Molecular Magnetism, VCH: New York, 1993; pp $159-164$.

19. Ruiz, E.: de Graaf, C : Alemany, P.; Alvarez, S. J. Phus. Chem. A 2002, 106, 4938 